congress is the meeting together and getting to know one's fellow-workers; and an expression of thanks is due to the organising committee under the joint presidentship of Profs. Wiesner and von Wettstein, with Dr. Zahlbruckner as the energetic secretary, to Prof. Flahault, the firm and genial president of the conference on nomenclature, and finally to Dr. Briquet, whose name must always be associated with the latest attempt to solve the vexed question of plantnomenclature.

At the final meeting, in response to an invitation from the Belgian Government voiced by Prof. Errera, Brussels was selected as the place of meeting for the third congress, which will be held in rgio.

A. B. Rendle.

\section{ENTRANCE EXAMINATION TO THE INDIAN FOREST SERVICE.}

N May II the Secretary of State for India issued the regulations for the forthcoming entrance examinations for the Indian Forest Service. Amongst the features of these regulations two are of considerable importance.

The age limit is raised to twenty-one years on January I preceding the examination, so that the average B.A. who graduates usually between twentyone and twenty-two may compete. The second point of interest is the schedule of the subjects in which he is to be examined.

According to the regulations given in the East India (Forest Service) Blue-book, Cd. $25^{23}$, the subjects in which the candidates are to be tested are four-chemistry, physics, botany, and zoology-and the schedules imply that the knowledge which the candidate is expected to exhibit is of a very limited description. Speaking roughly, the examination will be harder than the preliminary scientific examination which every candidate for a medical degree is obliged to take, but not much harder. Medical students generally pass their preliminary scientific examination during their first year, though there are cases in which they pass it while still at school. The Indian forestry students may pass their entrance examination in their third or fourth year. The Blue-book stated that each candidate must qualify in all four subjects, but for some reason or another-and probably because the entry under the new regulations is small-the Secretary of State for India has now still further lightened a very elementary examination, and is now advertising in our columns that zoology is optional. Thus men, who may be graduates, will be admitted into a great public service on an examination which comprises but three out of the ordinary four subjects which candidates for medical degrees normally pass in their first year, and judging by the schedules the amount in each subject to be "got up" is little more than in the preliminary examination for an M.B. degree.

When we remember that in the Indian Civil Service examination the standard of the subjects is that of an honours examination, and that a candidate takes not three subjects, but eight, nine, ten, or more, it is obvious that the Secretary of State is trying to recruit the forest officers from men of a markedly inferior intellectual range, and the strictures which were passed by Sir George King on the Indian foresters at the Dover meeting of the British Association will probably need repeating a few years hence.

The schedules are well adapted for an elementary pass or plough examination, but are ill adapted for a competitive examination. It will be very difficult, if not impossible, to select the best candidates competing in an examination carried on on these lines.

No. 1864 , voL. 72$]$

\section{NOTES.}

As important step in the direction of the adoption by this country of a decimal system of weights and measures has been taken by the Board of Trade. In reply to a resolution sent to the Board of Trade by the secretary of the Association of Chambers of Commerce, in which the Board was asked to authorise weights of $20 \mathrm{lb}$., 1o lb., and $5 \mathrm{lb}$. as aliquot parts of the cental, Lord Salisbury has written :- "With reference to your letter of March 14 last, in which you suggest that new denominations of weights of $20 \mathrm{lb}$., ro $\mathrm{lb}$, , and $5 \mathrm{lb}$. should be legalised for use in trade, the Board of Trade have given careful consideration to the representations which have been made, and they are prepared to assent to the application. Steps will, therefore, be taken for the preparation of standards of the same octagonal form as the present 5o lb. weight." The chambers consider that this concession will save time, labour, and expense, as the $5^{\circ} \mathrm{lb}$. weight has done already.

Commander Peary sailed on Sunday last to make a further attempt to reach the North Pole. Before leaving, he communicated various particulars respecting his expedition to Reuter's Agency. His plan is based upon the Smith Sound, or "American" route to the Pole, and his object is to force his ship to a base within 500 miles of the Pole itself, and then to sledge across the Polar pack. The Arctic ship Roosevelt, which has been specially built for this expedition, has been constructed so as to withstand the heavy ice pressure, and is so shaped that the pressure of the ice pack will have the effect of raising the vessel out of the water. The ship will carry a wireless telegraphic outfit, which, with one or two relay stations in Greenland, will keep her in communication with the permanent telegraph station at Chateau Bay, Labrador, and thence by existing lines with New York. By the same means communication with the expedition will be possible, at least for a portion of the distance, when in February next the sledge party leaves the Roosevelt for the northern dash. The ship will carry two years' supplies. With regard to the route to be followed, it is intended to establish a permanent sub-base at Cape Sabine, on the west coast of Smith's Sound, and, after securing the services of the necessary Eskimos, to force the vessel through Kane Basin and Kennedy and Robeson Channels to the northern coast of Grant Land or of Greenland, if the conditions should compel it, and there winter within 500 miles of the Pole. From these winter quarters a start north over the Polar pack will be made in February. The explorers will have available a probable period of five months in which to traverse the distance between their vessel and the Pole. In the event of the failure of the Roosevelt to force Kennedy and Robeson Channels during the first summer the dash for the Pole will have to be postponed until February, 1907.

THE seventy-third annual meeting of the British Medical Association will take place at Leicester from July 24 to 28 . Addresses in medicine and surgery will be delivered respectively by Dr. H. Maudsley and Mr. C. J. Bond, and, following the precedent of last year, a popular lecture will be given (on July 28 ) by Prof. Wm. Stirling, who will take as his subject the phenomena of fatigue and repose.

ThE Geologists' Association announces an excursion to Central Wales extending from July 24 to 29 . The head quarters are to be at Llandrindod Wells.

The first International Congress of Physiotherapy will be held at Liége from August I2 $_{2}$ to I $_{5}$ next. The questions proposed for discussion are, says the British Medical 